Supplement of Hydrol. Earth Syst. Sci., 20, 479-486, 2016

http://www.hydrol-earth-syst-sci.net/20/479/2016/

doi:10.5194/hess-20-479-2016-supplement

(C) Author(s) 2016. CC Attribution 3.0 License.

(c) (i)

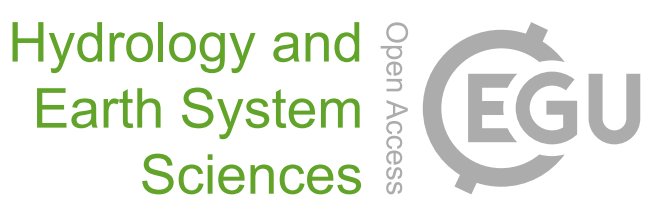

Supplement of

\title{
Does the Budyko curve reflect a maximum-power state of hydrological systems? A backward analysis
}

M. Westhoff et al.

Correspondence to: M. Westhoff (martijn.westhoff@ulg.ac.be)

The copyright of individual parts of the supplement might differ from the CC-BY 3.0 licence. 


\section{S1 Sensitivity of relation between $h$ and $G_{r}$ and $G_{e}$}

In the manuscript we assumed a linear relation between $h$ and $G_{r}$, scaled between zero and unity. Here we test different the sensitivities of the assumed relation between $h$ and one of the gradients.

\section{S1.1 Quadratic relation $h=f\left(G_{\mathrm{r}}^{2}\right)$}

The first relation we test is when $h$ is a function of $G_{\mathrm{r}}^{2}\left(k_{\mathrm{e}}\right)$ scaled between zero and unity:

$G_{\mathrm{r}}(h)=\min \left[G_{\mathrm{r}}^{2}\left(k_{\mathrm{e}}\right)\right]+\left(\max \left[G_{\mathrm{r}}^{2}\left(k_{\mathrm{e}}\right)\right]-\min \left[G_{\mathrm{r}}^{2}\left(k_{\mathrm{e}}\right)\right]\right) h$

To test the sensitivity of this relations, we constructed the Budyko curve for a dry spell of six months. Comparison with the Budyko curve obtained with the original relation were $h$ is assumed to be linear with $G_{\mathrm{r}}\left(k_{\mathrm{e}}\right)$ shows that the sensitivity is very small (S1.1)

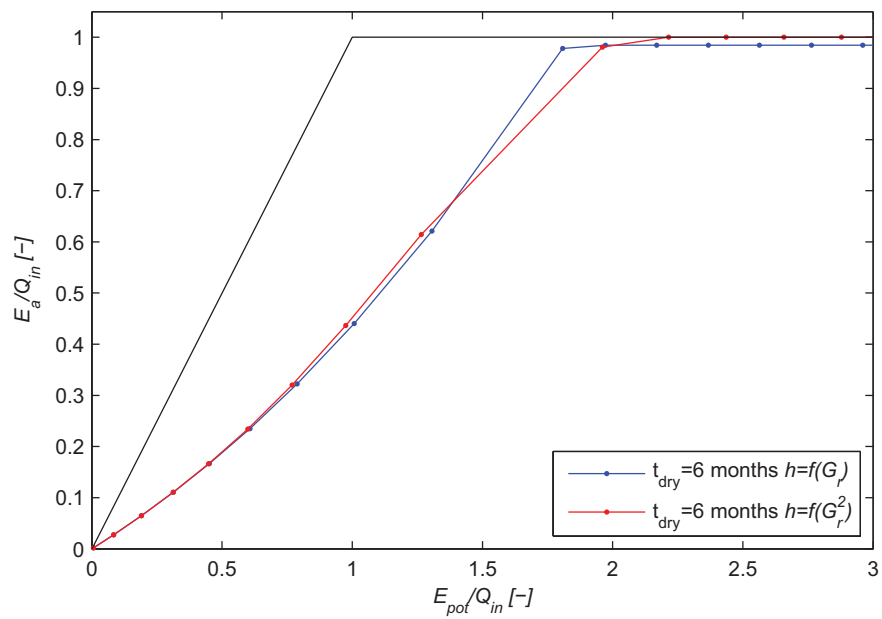

Figure S1.1. Sensitivity of a quadratic relation between $h$ and $G_{\mathrm{r}}\left(k_{\mathrm{e}}\right)$. 
S1.2 Linear relation between $h$ and $G_{\mathrm{e}}\left(k_{\mathrm{e}}\right): h=f\left(G_{\mathrm{e}}\right)$

Another option is to assume that $h$ is a linear function of $G_{\mathrm{e}}\left(k_{\mathrm{e}}\right)$, scaled between zero and unity. To apply this assumption, we had to adapt the gradients in such a way that i) at $h=0, G_{\mathrm{r}}=0$ and ii) $G_{\mathrm{r}}$ is a monotonously increasing with $h$. These two requirements resulted in two different choices for adapting the gradients: the first is to let $G_{\mathrm{r}}$ at the its minimum between $h>0$ and $h$ at the minimum of $G_{\mathrm{r}}$, while at $h=0, G_{\mathrm{r}}=0$; the second is to set $G_{\mathrm{r}}$ to zero between $h=0$ and $h$ at the minimum of $G_{\mathrm{r}}$ (Fig. S1.2a and b). The resulting Budyko curves are completely different from the original one (Fig. S1.2c). The main reason for this is that, to fulfil the requirements mention above at small absolute values of $\mu_{\mathrm{atm}}$, the gradients have to be adapted over a too large range of relative wetness.
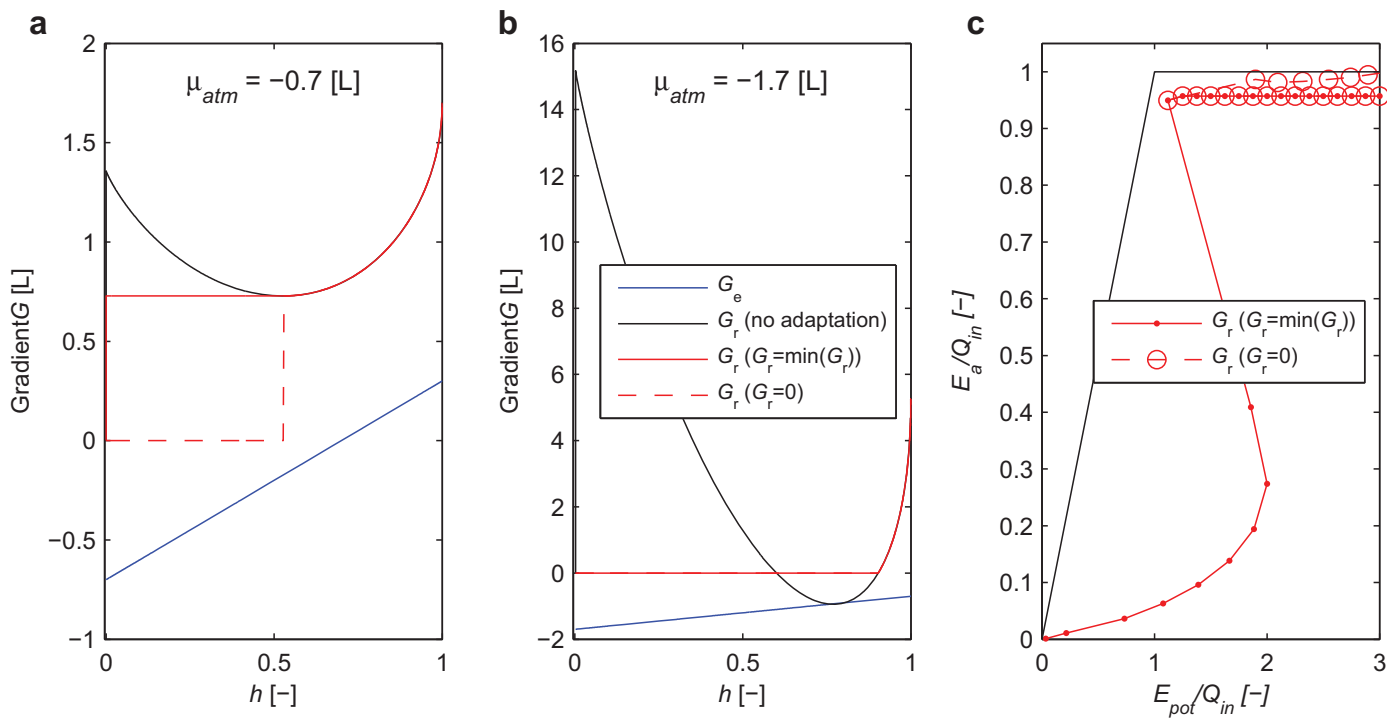

Figure S1.2. Gradients $G_{\mathrm{e}}$ and $G_{\mathrm{r}}$ for a) $\mu_{\mathrm{atm}}=0.7$ and b) $\mu_{\mathrm{atm}}=1.7$, and c) Budyko curves for the two different choices of adaptation of the gradients. 


\section{S1.3 Linear relation between $h$ and $-k_{\mathrm{e}}: h=f\left(-k_{\mathrm{e}}\right)$}

The last option we tested is the assumption of $h$ being a linear function of $-k_{\mathrm{e}}$, scaled between zero and unity. Both gradients have been derived as a function of $k_{\mathrm{e}}$ (Eq. 13 and 15). In order to avoid negative values for $G_{\mathrm{r}}$, adaptations were made in a similar way as to the relation between $h$ and $G_{\mathrm{e}}\left(k_{\mathrm{e}}\right)$. The adaptation were $G_{\mathrm{r}}$ is set to zero between $h=0$ and $h$ at the minimum of $G_{\mathrm{r}}$ resulted in a curve similar as in section S1.2 (Fig. S1.3). Adapting $G_{\mathrm{r}}$ such that $G_{\mathrm{r}}=\min \left(G_{\mathrm{r}}\right)$ between $h>0$ and $h$ at the minimum of $G_{\mathrm{r}}$, resulted in a Budyko curve reasonable for $\mu_{a t m} \leq-0.8$, while it gives completely different values for $\mu_{a t m}>-0.8$. Reason for this behaviour is that for $\mu_{a t m}>-0.8$, the gradient $G_{\mathrm{r}}$ is always large enough to avoid the water level becoming larger than $h$ at the minimum of $G_{\mathrm{r}}$, while the reservoir always becomes empty in-between two wet periods; even when $k_{\mathrm{e}}=0$. At these low relative wetness values $G_{\mathrm{r}}(h)$ is constant and an maximum in power only occurs when $k_{\mathrm{e}}$ is extremely large.
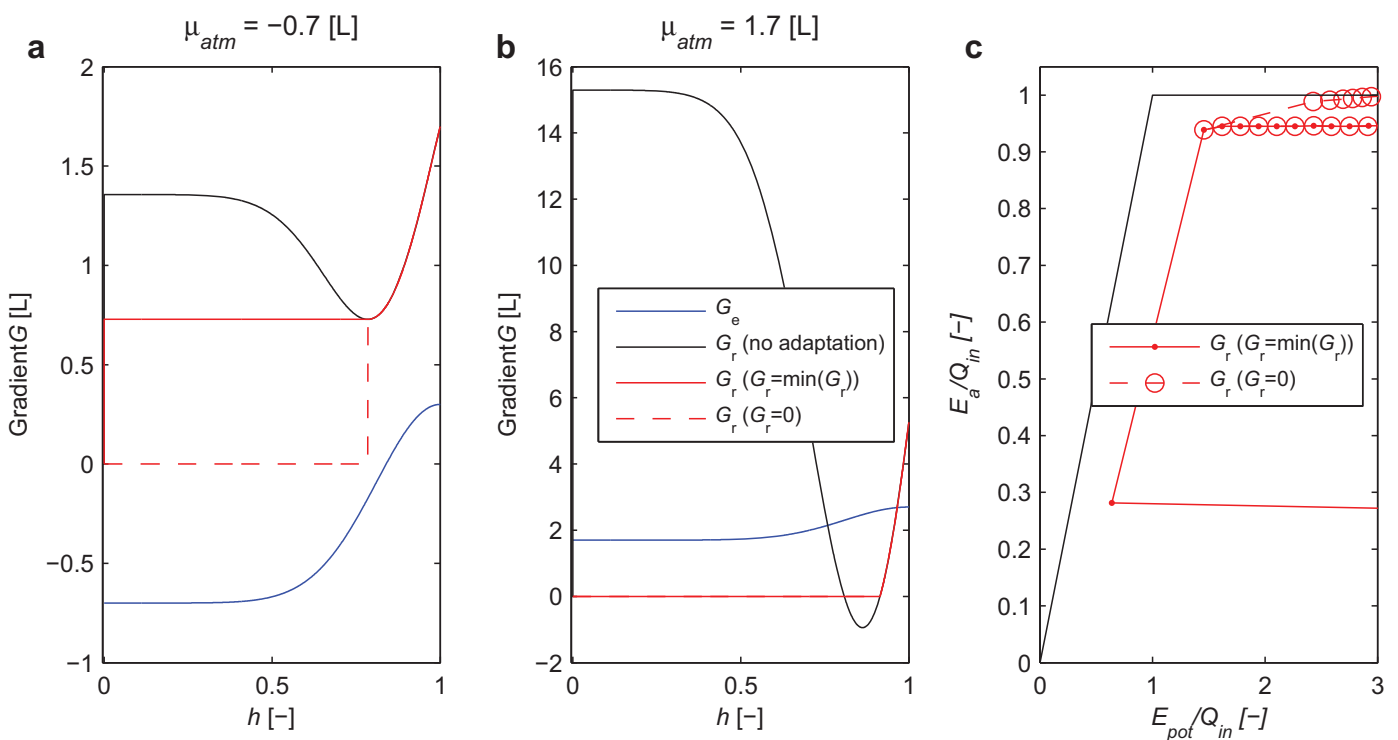

Figure S1.3. Gradients $G_{\mathrm{e}}$ and $G_{\mathrm{r}}$ for a) $\mu_{\mathrm{atm}}=0.7$ and b) $\mu_{\mathrm{atm}}=1.7$, and c) Budyko curves for the two different choices of adaptation of the gradients. 
S2 Boxplots of monthly precipitation and evaporation
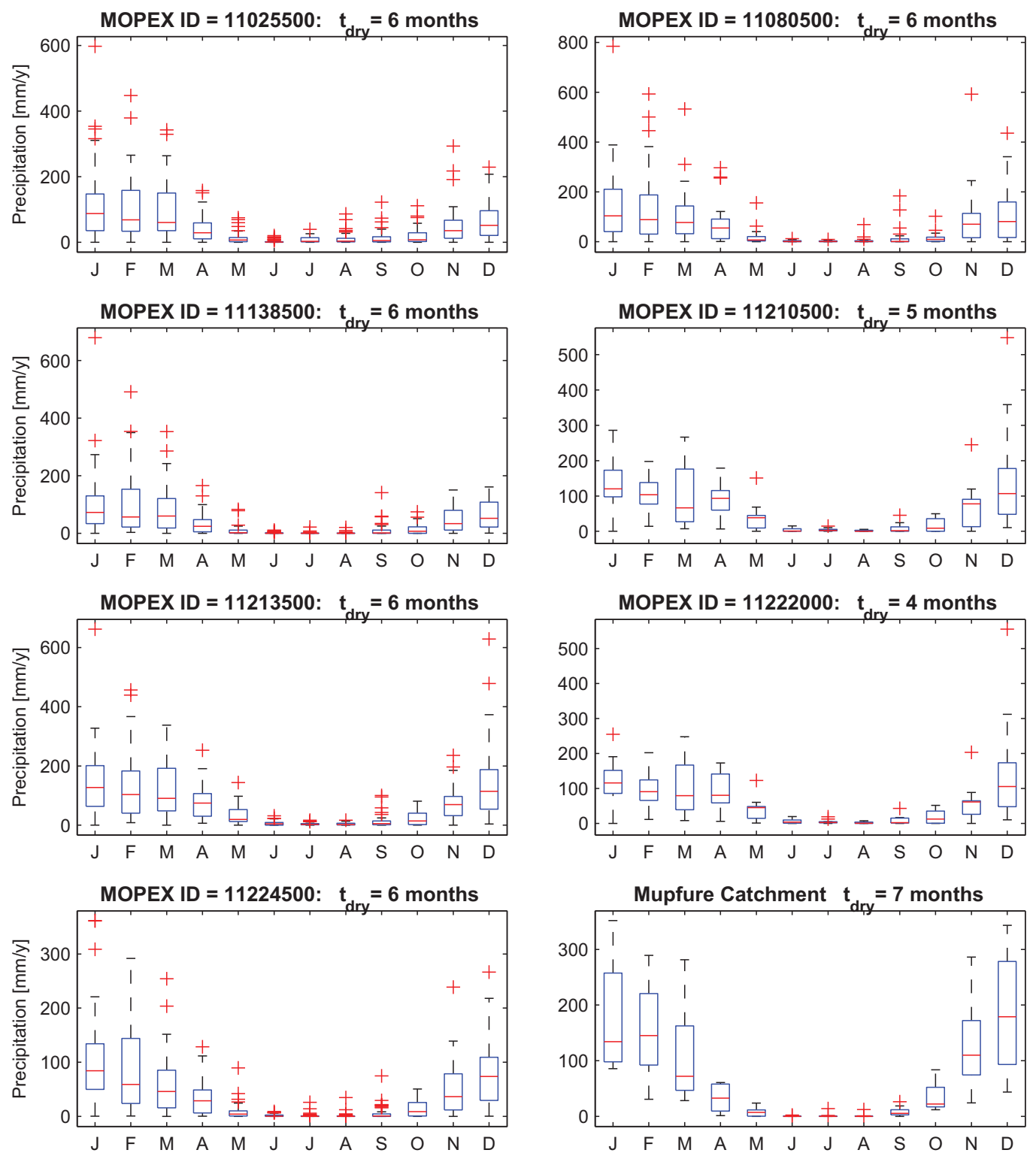

Figure S2.1. Boxplots of monthly rainfall of catchments with a clear distinct dry period. 

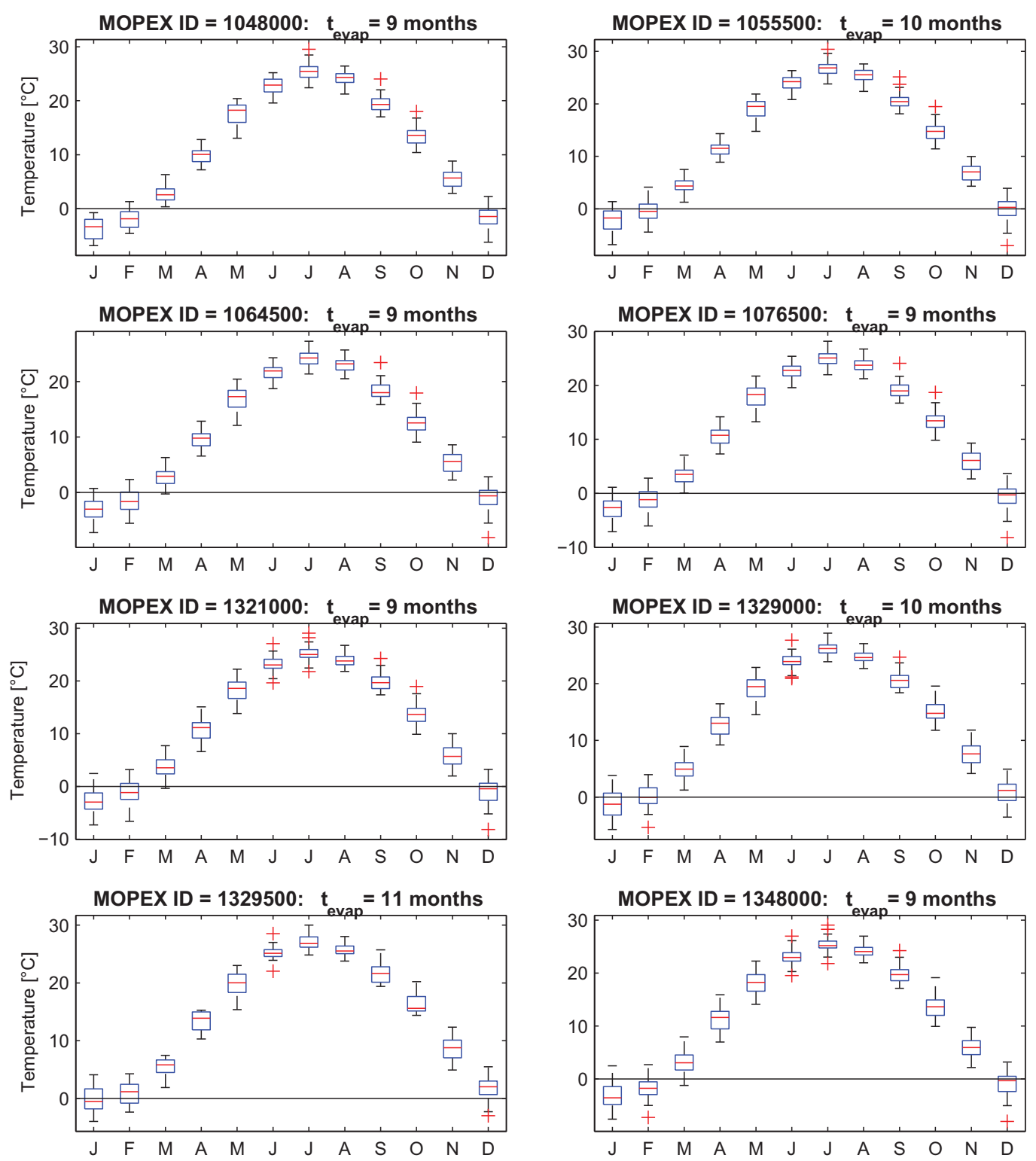

Figure S2.2. Boxplots of monthly temperature of catchment with at least one month of median monthly maximum temperatures below zero: these months are considered to have no actual evaporation. 